\title{
IMPERIO DEL DERECHO VERSUS IMPERIO DE LOS JUECES: UN ALEGATO POR EL PLURALISMO JURÍDICO*
}

\author{
RICHARD STITH ${ }^{\prime}$
}

RESUMEN: Trátase en el presente artículo que la concentración absoluta del poder de interpretación jurídica en un tribunal supremo es un error, sobre todo en una época en que los propios jueces alrededor del mundo están cada vez menos convencidos de que el derecho sea ciencia más que política. Se sostiene que la alternativa al monismo no es necesariamente el desorden. En vez de eso puede ser el pluralismo jurídico. La interpretación oficial del derecho puede ser dividida o equilibrada más que consolidada o eliminada completamente. Equilibrando acertadamente la separación de poderes y el sistema de frenos y contrapesos es posible que no se brinde una solución de principio a la tensión que subyace en el ideal de imperio del derecho, pero se ofrecen alternativas prácticas a la elección entre tiranía y desorden.

Palabras clave: Imperio del Derecho - Tribunales supremos - Pluralismo político - Interpretación del Derecho.

ABSTRACT: This paper states that the absolute concentration of legal interpretation power in a supreme court is an error; moreover in times when judges themselves around the world are less convinced that the law is more a science than it is politics. It is argued that the alternative to monism is not necessarily disorder. Instead, it could be Legal Pluralism. The official interpretation of the law can be divided or balanced rather than completely merged or eliminated. It is likely that with a correct balance between the powers' separation and the stoppage and counterbalance system there won't be a principle solution to the

Publicado originalmente en Political Thought (Ucrania), $\mathrm{N}^{\circ} 3$ (10), 1997, 31. Traducido por Jaime Arancibia Mattar, Profesor de Derecho Administrativo, Universidad de los Andes. El presente artículo contribuye al debate de la doctrina chilena en torno a la consolidación del control de constitucionalidad de la ley en un solo órgano jurisdiccional (Tribunal Constitucional), en desmedro del actual sistema que contempla además la participación de la Corte Suprema (artículo 80 de la Constitución). Esta propuesta ha sido aprobada recientemente por el Congreso Nacional en el marco del proyecto de reforma constitucional que elimina la competencia de la Corte Suprema para conocer del recurso de inaplicabilidad de la ley, con el objeto de traspasarla al Tribunal Constitucional (Boletines del Senado $N^{0}$ s 2.526-07 y 2.534-07).

1 Profesor de Derecho, Valparaiso University, Estados Unidos [redacción 22 junio 2004]. Artículo recibido el 2 de diciembre de 2004. Aceptado por el Comité Editorial el 16 de marzo de 2004. 
tension underlying in the ideal of the Rule of Law, yet practical alternatives are offered to the choice among tyranny and disorder.

Key words: Rule of Law - Supreme courts - Political pluralism Interpretation of the Law.

SUMARIO: Introducción. ¿Quién le teme al imperio del derecho? La infalibilidad como consuelo. ¿Puede confiarse a los tribunales supremos la función de aplicar correctamente el derecho en el siglo XXI? Teoría y práctica del pluralismo jurídico.

\section{INTRODUCCIÓN}

¿Es posible el imperio del derecho (rule of law)? El derecho, para imperar, debe ser impuesto. Pero cuando es impuesto, puede no ser el derecho mismo sino aquellos que lo imponen quienes imperen. Para sujetar estas autoridades firmemente al derecho, ellas también tendrían que estar sometidas no solo al derecho mismo sino a una fuerza aún más poderosa que podría ser igualmente arbitraria. De este modo, el solo esfuerzo por asegurar el imperio del derecho conduce a la creación de potenciales tiranos cada vez más poderosos.

Dicho de otro modo: si se suprimen la policía y los tribunales de justicia, con el solo objeto de dejar al pueblo sometido verdaderamente "no al hombre sino solo a Dios y al derecho"2, se estaría incitando al desorden. Pero, por otro lado, si se otorga a la policía o a la judicatura - $O$ a sus superiores-, plenos poderes para instar a la obediencia, se estaría abogando por una tiranía ilícita. El derecho existe en tensión tanto con el orden como con el desorden.

En principio, la única vía posible para eliminar esta contradicción, inherente al ideal de imperio del derecho, sería fortalecer a unos mandatarios finales que sean perfectamente desinteresados y sabios, de tal manera que puedan aplicar el derecho en forma infalible. El derecho puede imperar, puede ser absolutamente compatible con el orden, solo si las autoridades humanas -a quienes el derecho está confiado en último

2 Este antiguo ideal, inscrito en latín sobre la entrada de la Escuela de Derecho de Harvard, se interpreta comúnmente en el sentido de que nuestros superiores políticos están sometidos a normas jurídicas, por lo tanto, no podrían actuar en forma arbitraria o según su propia voluntad. Véase Mortimer R. KADISH y Sanford H. KADISH: Discretion to Disobey, Stanford University Press, 1973, 40-41. Sin embargo, la versión más fuerte, atribuida a Bracton, sostiene que este aforismo solo podría aplicarse en plenitud a alguien que, como el rey, no reconoce ningún superior político: Quod Rex non debet esse sub homine sed sub Deo et Lege. Catherine Drinker Bowen: The Lion and the Throne, Little, Brown and Company, Boston, 1956, p. 305. 
término-, están decididas y capacitadas para aplicar nada más que el derecho.

Tal vez, por temor al desorden por sobre todas las cosas, las naciones podrían estar dispuestas a confiar en esta infalibilidad o en algo parecido. Ellas podrían encomendar todo su sistema jurídico a un tribunal "supremo" o "constitucional" que desarrolle una interpretación jurídica supuestamente objetiva. De este modo, ambas consecuencias, desorden y tiranía, parecen ser evitadas a través de un sistema de expertos imparciales cuya correcta interpretación del derecho es vinculante para todos.

Este artículo sostendrá que la concentración absoluta del poder de interpretación jurídica en un tribunal supremo es un error, sobre todo en una época en que los propios jueces alrededor del mundo están cada vez menos convencidos de que el derecho sea ciencia más que política. Los políticos omnipotentes son tiranos en potencia. Sin embargo, la alternativa al monismo no es necesariamente el desorden. En vez de eso puede ser el pluralismo jurídico. La interpretación oficial del derecho puede ser dividida o equilibrada más que consolidada o eliminada completamente. Por ejemplo, en muchos países no existe un tribunal supremo único sino varios. Como se verá a continuación, este y otro tipo de soluciones funcionan sin mayores inconvenientes en los sistemas jurídicos del mundo. Las naciones que actualmente están elaborando o reformando sus constituciones no deberían sentirse obligadas a otorgar un poder de interpretación ilimitado a ningún tribunal.

Desde un punto de vista lógico, el derecho cuenta con dos mecanismos posibles para limitar el poder de cualquier tribunal supremo: la "separación de poderes" (separation of powers), que inhibe al tribunal supremo de controlar la interpretación jurídica de ciertos organismos judiciales y no judiciales; y la fórmula de "controles y equilibrios" (checks and balances), que faculta a ciertas entidades controladas por el tribunal para contrarrevisar las decisiones de este último. Cada enfoque, o una mezcla de ambos, es un término medio que reduce la probabilidad de tiranía sin incurrir en un riesgo de desorden inaceptable. Estas propuestas no brindan una solución de principio a la tensión que subyace en el ideal de imperio del derecho, pero ofrecen alternativas prácticas a la elección entre tiranía y desorden.

\section{¿QUIÉN LE TEME AL IMPERIO DEL DERECHO?}

Las constituciones recientes de muchas naciones, por ejemplo Ucrania $^{3}$, proclaman la fidelidad al "imperio del derecho" en contraste con el

Constitución de Ucrania, 28 de junio de 1996, Artículo 8. Asimismo, véase la Constitución de Nepal, adoptada a finales del siglo veinte, Preámbulo (Tercer Párrafo). 
imperio ilícito de los individuos. ¿Por qué es preferible estar sujeto a las leyes más que a los hombres y mujeres? Al menos cuatro razones se vienen rápidamente a la mente.

Primero, sin el "imperio del derecho" no puede existir un "imperio del derecho superior". Aquellos que reconocen un derecho no positivo (natural), $u$ otro derecho preexistente al Estado que exige respeto por los derechos fundamentales, necesariamente comparten el ideal de "imperio del derecho", aunque no lo consideren suficiente. Claramente, un tirano sin límites jurídicos no está obligado a respetar tales derechos básicos.

Segundo, sin el imperio del derecho no podría existir ninguna democracia de magnitud sustancial. Un sistema en que cada conflicto individual fuese juzgado por el voto mayoritario de la comunidad es prácticamente imposible, salvo que se trate de una unidad política increíblemente pequeña. En consecuencia, el gobierno por el pueblo solo será posible si la mayoría puede promulgar normas generales que sean aplicadas fielmente por la policía y los tribunales en los casos particulares. De esta forma, el imperio del derecho se hace necesario para que impere la voluntad del pueblo, aunque es obvio que este imperio no es suficiente, ya que los dictadores no democráticos también podrían imponer su voluntad a través de normas generales como constituciones y leyes.

Tercero, el imperio del derecho asegura la libertad personal y económica. El conocimiento anticipado de la manera en que reaccionarán los funcionarios públicos frente a crímenes y disputas civiles permite a los individuos planificar sus vidas y sus inversiones. Incluso, un régimen no democrático que ignora los derechos fundamentales básicos podría garantizar una esfera de individualidad en la medida que adhiera a sus propias normas previamente anunciadas, en vez de cambiarlas ex post facto.

Cuarto, el imperio del derecho legitima y de este modo brinda estabilidad a los gobiernos. Los valores mencionados anteriormente (derechos humanos, democracia, y libertad personal) figuran dentro de las principales razones por las cuales hombres y mujeres están dispuestos a tolerar y soportar estar gobernados. Un gobierno que ignora el imperio del derecho no solo está afectando estos tres valores sino también su propia existencia. En la medida que la estabilidad sea algo bueno, preservar el Estado es otra razón para preferir el imperio del derecho por sobre el imperio discrecional de los líderes políticos.

El alto grado de atención e interés que despierta el imperio del derecho se traduce en la necesidad de verlo efectivamente respetado y exigido. La falta de mecanismos de control o vigilancia favorece el incumplimiento del orden jurídico, ya sea por error o mala voluntad de los sujetos obligados. De igual modo, un presidente o un legislador podría malinterpretar o ignorar una norma constitucional con tal de obtener resultados políticos, a pesar de su juramento de respetar la Carta Fundamental. Por regla general, los tribunales de justicia son los encargados de 
controlar jurídicamente el ejercicio de dichos poderes, por ejemplo, a través de la revisión de los actos legislativos y de ciertas declaraciones de inconstitucionalidad. En atención a que los tribunales pueden sostener interpretaciones erróneas del derecho, ya sea en forma intencional o accidental, sus decisiones son revisadas a menudo por un tribunal superior, y las sentencias de este último son controladas a su vez por una corte de mayor jerarquía, llegando finalmente a un tribunal supremo cuya interpretación del derecho es definitiva para el caso particular.

Con el objeto de lograr uniformidad de resultados, pero evitando la tramitación de litigios similares ante la misma autoridad final, parece sensato que la interpretación jurídica sea obligatoria no solo para las partes directamente involucradas en el conflicto, sino respecto de todo el sistema jurídico. Este objetivo puede lograrse ya sea a través de una versión "horizontal" del stare decisis (precedente obligatorio), según el cual no resulta procedente ventilar antiguos asuntos porque el más alto tribunal de apelaciones está decidido a no admitir nunca un error y cambiar de opinión; o también mediante una declaración jurídicamente obligatoria de que todos los ciudadanos e instituciones, con excepción de aquel tribunal, quedarán sometidos a la interpretación jurídica del juez supremo con prescindencia de su propio criterio acerca de lo que es justo, lo que podría ser calificado como una versión "vertical" del stare decisis. La Corte Suprema de Estados Unidos nunca ha invocado la primera versión (horizontal) del stare decisis en forma absoluta, y solo comenzó a aplicar la segunda (vertical) en 1958, al declarar que sus interpretaciones de la Constitución tenían un rango jurídico equivalente al de la propia Constitución ${ }^{4}$. La Constitución de Ucrania obtiene un resultado casi idéntico al entregar "la interpretación oficial de la Constitución de Ucrania y de las leyes de Ucrania"5 al nuevo Tribunal Constitucional, cuyas decisiones "son obligatorias en todo el territorio de Ucrania, son definitivas, y no pueden ser apeladas" 6 .

4 Cooper v. Aaron, 358 U.S. 1(1958). En este caso la Corte atribuye un rango constitucional a su propia interpretación de la Carta Fundamental, lo cual se asemeja a una aplicación conjunta de las dos versiones del stare decisis. Sin embargo, la Corte no pudo haber pretendido dicho resultado, dado que ha continuado modificando sus precedentes según la ocasión, en circunstancias que no podría hacerlo con la propia Constirución. De esta forma, la doctrina de Cooper nos conduce finalmente a la idea de que solo la Corte está por sobre el derecho, en el sentido de que todos salvo la Corte misma deben considerar sus interpretaciones más recientes como ley suprema. En el caso Planned Parenthood v. Casey, 505 U.S. 833 (1992), el máximo tribunal volvió a insistir en la fuerza horizontal de stare decisis, al sostener que no puede modificar una interpretación anterior por la sola razón de considerarla equivocada. Sin embargo, en la práctica, parece seguir invalidando interpretaciones por este solo hecho. Véase Lawrence v. Texas, 123 S.Ct. 2472 (2003).

5 Constitución de Ucrania, art. 150 (2). Véase también Art, 147.

6 Id, El contextn de esta norma muestra claramente que tales interpretaciones obligan con efecto erga omnes, contra todos, no solo respecto de las partes del litigio. 
Por muy sensato que pudiere parecer en dicho contexto jurídico, la sola idea de "interpretación vinculante" es un espécimen muy extraño. Por ejemplo, sería chocante e incluso ridícula en un contexto literario. Una sociedad abierta no podría tolerar una interpretación oficial y vinculante de -por ejemplo- SHAKESPEARE, no obstante provenga de un intérprete de reconocida imparcialidad y sabiduría. La razón es simple. La sola idea de interpretación contiene la noción de un informe y con él la idea de fidelidad hacia aquello sobre lo que uno está hablando. Aunque nosotros sabemos que cada interpretación es filtro y conducto a la vez, lo que realmente diferencia a una interpretación de una creación es el elemento de fidelidad hacia un original preexistente. Dicho de otro modo, el valor de una interpretación proviene -en primer lugar- no de su contenido mismo sino de aquello que es interpretado. Una interpretación es una fuente secundaria de información a la que recurrimos cuando no somos capaces de entender la fuente primaria por nuestros propios medios. Pero dado que nuestro objeto original de entendimiento es la fuente primaria, también nos interesa enmendar los errores de la fuente secundaria una vez que contamos con los instrumentos para hacerlo. Por esta razón, continuando con nuestro ejemplo, si la fuente secundaria se vuelve obligatoria significaría que se ha perdido el interés por comprender en forma precisa la fuente primaria, es decir, las obras de SHAKESPEARE. Pero, ¿no era que la fuente secundaria tenía validez solamente porque aplicaba la fuente primaria? De esta forma, la "interpretación vinculante" carece de sentido.

Se podría decir que en el ámbito jurídico la situación es diferente. Aunque sí importe la fidelidad a los textos jurídicos, especialmente a los de rango constitucional, podría sostenerse que la necesidad de uniformidad jurídica es tan grande que la fidelidad textual debe ser sacrificada. Tendríamos que adherir a las interpretaciones oficiales claramente erróneas, incluso en materias de importancia fundamental, porque de lo contrario el conocimiento público del derecho sería menos uniforme.

Es preciso señalar, sin embargo, que esta percepción de la interpretación vinculante como necesidad de orden público ha surgido en una época relativamente reciente. De hecho, la historia del derecho europeo continental está marcada por un repetido rechazo de la idea de que aquellos que aplican el derecho deben obedecer la interpretación jurídica de otro (una interpretación que les parece errónea) en vez de aplicar el derecho en forma directa.

Todos sabemos que la tradición central de Europa, a diferencia de la de Gran Bretaña, rechazó la idea de stare decisis y otras doctrinas que pudieran conducir a un gobierno de los jueces. La prohibición francesa de citar precedentes judiciales y la costumbre alemana de utilizar la frase "opinión dominante" para referirse exclusivamente al criterio (no vinculante) de los académicos y no al de los jueces, son ejemplos inequívocos 
de la negativa a otorgar un carácter infalible o legalmente obligatorio a las interpretaciones judiciales. En términos simples, en Europa siempre ha sido posible sostener que los tribunales se han equivocado en la interpretación de un código u otro documento jurídico. Según la extraña doctrina del "precedente obligatorio", semejante afirmación tendría tan poco sentido como sostener que las leyes del Parlamento son erróneas. Una interpretación que obliga jurídicamente es una fuente secundaria que se ha transformado en fuente primaria. Es el derecho mismo. Por lo tanto, no es posible que contenga un error acerca del derecho.

El famoso proverbio del obispo inglés HOADLY refleja muy bien una de las principales razones del tradicional temor europeo a la interpretación vinculante: "Quien sea que detente una autoridad absoluta para interpretar cualquiera de las leyes escritas o formuladas oralmente, él es el legislador para todos los efectos, y no la persona que las escribió o proclamó primero"7 . En consecuencia, cualquier ciudadano que esté particularmente interesado en un texto legal no permitirá que este sea reemplazado por una interpretación. Ya sea porque el derecho comprende los derechos naturales, o porque representa la voluntad del pueblo, o porque da origen a expectativas privadas, o por otras razones, los europeos han sido "legalistas" costa de un continuo debate acerca de su significado.

Es decir, el rechazo europeo a la práctica anglosajona de legislación judicial parece abrigar una cierta tensión con las primeras tres razones que apoyan el imperio del derecho: Si el juez es el legislador absoluto, entonces está por encima de los derechos humanos y de la voluntad del pueblo. Y dado que sus sentencias alteran con efecto erga omnes obligaciones jurídicas anteriores, su "legislación" adolece de ser ex post facto y sin aviso previo.

El rechazo de la idea de interpretación vinculante de una constitución rígida (es decir, difícil de enmendar) podría surgir incluso en lugares donde la doctrina del stare decisis se aplica respecto de materias jurídicas comunes, donde la corrección legal de los errores judiciales es relativamente fácil. La razón para esta diferenciación es obvia. Los peligros de una interpretación vinculante son mucho más graves cuando se trata de normas que no pueden ser modificadas fácilmente. El grado de supremacía que los tribunales pueden alcanzar respecto de fuentes jurídicas de difícil enmienda puede ser mucho más permanente que el ejercido sobre leyes y constituciones flexibles. El presidente norteamericano Thomas

H.L.A. HarT; The Concept of Law, 2nd ed., Oxford Universicy Press, 1994, p. 141.

Franz WIEACKER ha llamado "personalismo", "juridicismo", e "intelectualismo" a las tres invariables en la cultura jurídica Europea. "Foundations of European Legal Culture". traducida y concordada por Edgar BODENHEIMER, en American Journal of Comparative Law, $\mathrm{N}^{\circ} 38,1990$, pp. 19-27. 
JEFFERSON una vez escribió que la "opinión que otorga a los jueces el derecho de decidir (el significado de la Constitución para las ramas Legislativa y Ejecutiva del gobierno) haría de la judicatura una rama despótica" 9 . El Presidente Abraham LinCOLN, en su primer discurso inaugural de 1861, advirtió que si "la política del Gobierno es determinada en forma irrevocable por las decisiones de la Corte Suprema... en acciones personales entre partes, el pueblo habrá dejado de ser su propio gobernante" 10 . Estos hombres vieron claramente que la doctrina de la interpretación constitucional obligatoria puede conducir a una tiranía sin control. La fidelidad a un orden constitucional podría demandar resistencia hacia una Corte que infringe principios esenciales de la Carta Fundamental ${ }^{11}$.

El argumento que hemos venido desarrollando podría sintetizarse del siguiente modo: el "imperio del derecho" es un ideal valioso. Con el objeto de garantizar la parte de "imperio" de este ideal, parece sensato confiar el derecho a un tribunal supremo. Sin embargo, si se abusa de esta confianza, surge la temida posibilidad de un imperio sin derecho, i.e. de despotismo judicial. Tanto en Estados Unidos como en Europa se han realizado importantes esfuerzos por evitar este resultado. Básicamente, se ha preservado la posibilidad de disenso jurídico, de un desacuerdo significativo con las interpretaciones jurídicas realizadas por el más alto tribunal.

¿Es suficiente, sin embargo, hacer lo que JeFFERSON y LiNCOLN parecen sugerir, es decir, reconocer el derecho de las otras ramas del Gobierno a resistir una corte que es inconstitucionalmente despótica? Acuérdense: es perfectamente posible que una misma facción política pueda dominar las tres ramas del gobierno y que las tres juntas conspiren para afectar el régimen constitucional, como ocurrió en la Alemania nazi. En tal caso, ¿qué exige la fidelidad al derecho o a la Constitución?

9 Carta a Abigail Adams, 8 Writings of Thomas Jefferson, Ford. Ed,, 1897, pp. 310-311; en PAUL BREST, Processes of Constitutional Decisionmaking, Little, Brown and Company, Boston, 1975, pp. 70-71.

10 Messages and Papers of the Presidents 5, 9, Richardson ed., 1897, en ibid, p. 71.

11 En Ucrania existe una complicación adicional. La nueva Constitución establece que las interpretaciones del Tribunal Constitucional son obligatorias para todos. Entonces, ¿cómo podría ser resistido alguna vez dicho Tribunal en nombre de la Constitución? La respuesta podría ser que el poder de interpretar es distinto al poder de modificar. De este modo, si el Tribunal Constitucional pretendiera modificar la Constitución bajo la apariencia de una mera interpretación, la fidelidad al orden constitucional podría demandar una resistencia a las órdenes del Tribunal. Se trata del mismo argumento esgrimido por el Tribunal Constitucional de Alemania para oponerse a que el Tribunal de Justicia de la Unión Europea enmiende los tratados bajo la rúbrica de una mera interpretación. Véase el Maastricht Vertrag Urteil, BVerfGE 89, 155 (1993). 


\section{EL PROFESOR SANFORD}

LEVINSON ha señalado que, en definitiva, la única forma de garantizar el respeto de la Constitución por parte de quienes la aplican es que los propios ciudadanos controlen la constitucionalidad de los actos judiciales u otros de carácter oficial, y se resistan a colaborar con aquellos que son abiertamente antijurídicos. Este autor sostiene que "la revisión ciudadana es una necesidad vital para cualquier sistema político que pretenda denominarse constitucional" 12 . Tal vez en consideración a la captura nazi de todas las instituciones del Estado, Alemania ha consagrado expresamente el derecho constitucional de resistencia a los actos inconstitucionales de jueces y otros funcionarios. El artículo 20(4) de la Carta Fundamental declara que "todos los alemanes tienen el derecho de resistir a cualquier persona o personas que pretendan abolir el orden constitucional, no existiendo otra vía de protección posible"13. De este modo, el imperio del derecho en Alemania contempla el derecho de resistir a todos los gobernantes en nombre del derecho.

Pero si la elevación del "imperio" por sobre el "derecho" fuera de temer, ¿no lo sería también la elevación del "derecho" por sobre el "imperio"? Si bien la fidelidad de los ciudadanos a los gobernantes impide el desorden al precio de una posible tiranía, la fidelidad de los ciudadanos al derecho impide la tiranía al precio de un posible desorden. ¿Qué pasaría si muchos de los alemanes radicalizados concluyeran que el régimen jurídico actual es inconstitucional en su totalidad? Posiblemente, la autorización explícita para resistir podría contribuir al surgimiento del $\operatorname{caos}^{14}$.

¿Quién le teme al "imperio del derecho"? Nuestra respuesta debería ser "todos nosotros". Porque esta idea autocontradictoria puede conducir hacia una concentración del poder sin control, y hacia una descentralización del poder sin límites, siendo ambas posibilidades temibles.

\section{LA INFALIBILIDAD COMO CONSUELO}

Solamente existe una vía conceptualmente posible para escapar del enigma que hemos estado analizando. La razón principal por la que el

12 Constitucional Faith 55, Princeton University Press, 1988.

13 El contexto de esta norma sugiere que la resistencia podría ser en contra de las tres ramas de gobierno, incluyendo la judicial. La subsección anterior, Artículo 20(3), establece que "La legislación deberá estar sujeta al orden constitucional; el Ejecutivo y la judicatura deberán estar obligados por el derecho y la justicia".

14 Es posible que por esta razón Ucrania haya rechazado una norma asi de explícita en su nueva Constitución. El borrador de la Constitución de Ucrania, de 20 de febrero de 1996. contenía (en el Arrículo 14) una versión del artículo 20(4) alemán redactada en rérminos de mayor cautela. 
imperio del derecho tiende a degenerar en tiranía o desorden es la naturaleza indeterminada de la interpretación, que sujeta a todos los intérpretes a la posibilidad de error y a la tentación de manipulación. Si solo existiera un intérprete final, la vaguedad de su interpretación haría posible el despotismo; sin embargo, si existieran varios intérpretes, podría surgir el desorden. Por otro lado, si la interpretación fuera infalible, no habría ningún peligro, sin importar el número de individuos a quienes se les otorgó el poder de interpretación final.

La naturaleza de nuestro problema podría entenderse mejor a través de una analogía religiosa. Como el mismo profesor LEviNSON ha señalado ${ }^{15}$, la relación de los cristianos con la Biblia es similar en muchos aspectos a la relación de los ciudadanos con la constitución. La Biblia es, por así decirlo, la Constitución de la Cristiandad. Pero ¿quién tiene el poder final para interpretar la Biblia? Los cristianos protestantes han señalado que si el Papa fuera el único intérprete final, él podría manipular las escrituras para sus propios fines, transformándose en un tirano. Los cristianos católicos han respondido que si cada cristiano siguiera la "sola scriptura", sin confiar en la autoridad jerárquica, la cristiandad estaría dividida para siempre por múltiples interpretaciones erróneas.

En respuesta a la objeción protestante frente al Papa, los católicos han esgrimido la infalibilidad papal. El Pontífice, se dice, está sujeto al error y al prejuicio como todo ser humano. Sin embargo, cuando el Papa se pronuncia sobre materias religiosas fundamentales sus interpretaciones gozan de infalibilidad debido a la intercesión del Espíritu Santo. Los protestantes no cuentan con una réplica tan contundente. Ellos no pueden argumentar que el Espíritu Santo conduce a cada individuo lector de la Biblia hacia la verdad de modo infalible, porque el hecho de que muchos lectores discrepen abiertamente significa que no todos pueden estar en lo correcto. Pero los protestantes podrían sugerir que un creyente realmente humilde y piadoso encontrará en la Biblia, con el auxilio del Espíritu Santo, una interpretación correcta al menos para la situación particular.

Dado que somos pocos los que creen que el Espíritu Santo guía a los jueces u otros intérpretes seculares del derecho hacia el resultado correcto, parece poco probable que alguien proponga la infalibilidad como solución para nuestra antinomia en materia de derecho positivo. Y ciertamente, nadie ha sostenido nunca que cada ciudadano es capaz de entender todo el derecho nacional en forma infaliblemente correcta. Sin embargo, lo más curioso es que a menudo se atribuye un carácter infalible -o algo muy parecido- a la interpretación que realizan los tribunales supremos. Por ejemplo, se ha señalado que cuando el Pleno de la Corte Supre-

15 Op. cit. 
ma de la antigua Unión Soviética emitía "interpretaciones vinculantes", no añadía ni sustraía nada al derecho, sino que solo explicaba el verdadero significado de la norma, que ya tendría que haber estado claro para un lector cuidadoso ${ }^{16}$. La presunción común de la Corte Suprema de Estados Unidos (de que simplemente ha descubierto el verdadero significado de la Constitución) es muy similar ${ }^{17}$, aunque queda refutada por la falibilidad revelada por los ocasionales cambios de criterio de dicha Corte. (Si la propia Corte declara que ha cometido un error, entonces necesariamente lo ha cometido, ya sea en su primera interpretación, o en su declaración de que la interpretación anterior estuvo errada).

Nadie duda que los expertos jurídicos dominan una terminología técnica más amplia que la de los no letrados. Sin embargo, la sola designación de estos expertos en un tribunal supremo o constitucional, bajo la asunción (errónea por supuesto) de que son los más calificados y menos prejuiciados de la nación, no garantiza por sí misma la adopción de mejores decisiones que las que podrían adoptar incluso personas no letradas, sin educación y dogmáticas. La pregunta crucial es si el conocimiento experto, "ciencia jurídica", determina la interpretación. Si una "expertise" especial solo añade capas de complicación a los argumentos jurídicos, sin asegurar una elección que resulte obvia para observadores inteligentes y justos, entonces no es tan confiable después de todo.

\section{¿PUede CONFIARSE a LOS TRIBUNALES SUPREMOS LA FUNCión DE APLICAR CORRECTAMENTE EL DERECHO EN EL SIGLO XXI?}

La historia de la interpretación en el siglo veinte ha sido principalmente una de evolución desde un cientismo o conceptualismo jurídico supuestamente apolítico, a un activismo o nominalismo jurídico abiertamente orientado a los resultados. Esto es, la noción antiplatónica ha ganado terreno en aquello de que los conceptos jurídicos no pueden ser verdaderos o falsos, no se refieren necesariamente a ninguna realidad

16 En tal sentido, el profesor Christopher OSAKWE ha señalado que: "Estas interpretaciones orientadoras constituyen una aplicación del verdadero significado del derecho o de una norma individual de derecho, pero no crean en sí mismas una nueva norma jurídica. Estas explicaciones contienen la interpretación de las normas operativas que resulta evidente incluso $\sin$ necesidad de tales orientaciones. De ahí que las explicaciones no agregan nada nuevo a la norma, ni reducen su efecto; ellas simplemente definen su verdadero contenido". "Contemporary Soviet Criminal Law: An Analysis of the General Principles and Major Institutions of Post-1958 Soviet Criminal Law", Georgia Journal of International and Comparative Law, $\mathrm{N}^{\circ} 6,1976$, note 20 at 442.

17 El juez Marshall, en el caso original que reconoce el poder de la Corte Suprema para controlar la legislación del Congreso, presupone que la Corte, y solo la Corte, entiende el verdadero significado de la Constitución. Marbury v. Madison, 5 U.S. (1 Cranch) 137 (1803). 
dada; por lo tanto, las normas jurídicas que contienen tales conceptos pueden y tienen que ser utilizadas para generar cualquier resultado que desee el intérprete final de las normas. En América, este nominalismo filosófico ha existido hace tiempo bajo el irónico apelativo de "Realismo Jurídico" 18 . Sin embargo, para efectos de este artículo, conviene emplear la expresión "no interpretativismo" ${ }^{19}$, dado que esta doctrina sostiene que la interpretación fiel es imposible. El significado de un texto existe solamente en el pensamiento del lector, no en el texto mismo. Entonces, de ser así, como concluyó un Realista temprano, "el ideal de un gobierno de leyes y no de hombres es un sueño"20.

Desde luego, es cierto que en el resto del mundo el nominalismo jurídico no ha sido tomado tan en serio como en los Estados Unidos. Sin embargo, esta circunstancia no impedirá la futura expansión del escepticismo y cinismo norteamericano a Europa y otros lugares del mundo en este siglo veintiuno. Las razones de este fenómeno expansivo no tienen exclusiva relación con el progresivo avance de las comunicaciones globales. La jurisprudencia no conceptual y el activismo judicial adquirieron una mala reputación en la primera mitad del siglo veinte al ser identificados con el nazismo y el fascismo. En Alemania (en gran parte con éxito) y en Italia (con magros resultados) los jueces fueron obligados a ignorar las normas formales del derecho con el fin de asegurar el sentido común (visto, desde luego, a través de los ojos de las ideologías entonces dominantes). En respuesta inmediata, gran parte del pensamiento liberal fuera de norteamérica reafirmó temporalmente la idea de "derecho como un sistema de normas" en forma tan categórica que la mera posibilidad de activismo judicial nominalista pudiera ser olvidada ${ }^{21}$. Pero ahora ha transcurrido más de medio siglo. Y el peso norteamericano no se disminuye.

$\mathrm{La}$ indiferencia hacia las normas en beneficio de los resultados goza hoy en día del favor de la izquierda en Europa. El "uso alternativo" del derecho en España y un movimiento similar en Italia constituye un tipo de "Realismo Jurídico" incluso más descaradamente activista que aquel que se da en Estados Unidos.

Los nuevos movimientos literarios y filosóficos europeos también se han unido al Realismo Jurídico norteamericano y a las pretensiones de la izquierda de crear un cierto sinergismo. Con el surgimiento de pensado-

18. Véase American Legal Realism, editado por William W. FISHER III et al. Oxford University Press, New York, 1993. Para un excelente resumen histórico de esta escuela, véase Edward A, PURCell, Jr.: The Crisis of Democratic Theory, capítulos 5 y 9, University Press of Kentucky, 1973.

19 Véase John Hart ElY: Democracy and Distrust, para un uso temprano de este término en sentido un poco diferente, Harvard University Press, 1980.

20 Hessel E. YUtema: "The Hornbook Method and the Conflict of Laws", Yale Law Journal, $\mathrm{N}^{\circ} 37,480$. Citada por Purcell (n. 18), p. 89.

21 Véase a modo general J.M. Kelly: A Short History of Western Legal Theory, Clarendon Press, Oxford; Oxford University Press, New Cork, 1992. 
res europeos como DERRIDA ${ }^{22}$ y LYOTARD ${ }^{23}$, se ha vuelto casi banal negar que un texto literario pueda tener cualquier significado distinto de aquel construido por su intérprete. Sería extraño no aplicar dicho "deconstructivismo" 24 también a los textos jurídicos.

Sobre todo en el mismo corazón jurídico de Europa ha surgido un activismo judicial casi incomparable. La sentencia del Tribunal de Justicia de la Unión Europea en el caso Costa v. ENEL, con su doctrina de effet utile, ha conseguido elaborar hasta un nuevo Grundnorm por encima de las constituciones nacionales, y ha impuesto esta nueva manera de juzgar a la jurisprudencia nacional en todo aquello que tenga que ver con la Unión ${ }^{25}$.

Por estas razones -influencia norteamericana, izquierdismo político, filosofía deconstruccionista, y el gran ejemplo del Tribunal de la UE- no parece realista imaginar que al menos los jueces tradicionales en Europa y otros lugares alrededor del mundo van a permanecer en la tradición de la ciencia jurídica conceptualista. La idea de un juez supremo como experto científico, neutral y relativamente infalible es inverosímil para muchos hoy en día, y es poco probable que los jueces pretendan realizar lo que es considerado imposible por ellos y sus pares. Si a los jueces se les dice que tienen que ser políticos -incluso si esta aseveración es filosóficamente falsa- es probable que ellos se vuelvan políticos (y así, tal vez, tiranos por encima del derecho).

Al tenor de estas y otras consideraciones ${ }^{26}$, distinguidos observadores han comprobado la desaparición de la tradición de la ciencia jurídica en Europa. John Henry MERRYMAN, un prominente defensor del estilo de práctica jurídica americana, señaló hace tiempo que "la ciencia jurídica germana siempre ha sido objeto de sátira, ridículo y ataque directo por parte de juristas en Alemania y otras partes. Recientemente,... estas críticas han comenzado a surtir mayor efecto" 27.

MERRYMAN llegó hasta el extremo de declarar que una "transformación fundamental" 28 está ocurriendo en la tradición jurídica de Europa,

22 Véase a modo general, Jacques DerRIDA: Of Grammatology, Gayatri Chakravorty Spivak trans, John Hopkins Press, Baltimore, 1976.

23 Véase a modo general, Jean-Francois LyOTARD: The Postmodern Condition: A Report on Knowledge, Geoff Bennington y Brian Massumi trans., University of Minnesota Press, 1979.

24 Véase a modo general, Christopher NORRIS and Andrew BENJAMín: What is Deconstruction?, St. Martin's Press, New York, 1989.

25 6/64 [1964] ECR 585, [1964] CMLR 425. Véase para un argumento más desarrollado: STITH, Richard y WeILER, J.H.H.: Dos visiones norteamericanas de la jurisdicción de la Unión Europea, Universidad de Santiago de Compostela, 2000.

26 Véase John Henry Merryman: The Civil Law Tradition, 2nd ed, Stanford University Press, 1985 , pp. $142-50$.

27 Id., p. 147.

28 Id., p. 151. 
que en ciertos aspectos se muestra más cercana a la tradición norteamericana contemporánea.

El creciente escepticismo contemporáneo respecto de la objetividad del proceso de interpretación ha afectado progresivamente la confianza depositada en un tribunal supremo para que aplique el derecho correctamente. Así como la creencia en la ciencia jurídica se desvanece, la única analogía secular de la infalibilidad papal desaparece. De este modo, la facultad de emitir interpretaciones vinculantes solo aseguraría el orden, pero no un derecho preexistente.

Esta conclusión acerca de los cambios de percepción respecto de la interpretación jurídica se ve confirmada por un cambio de criterio sobre la naturaleza de las constituciones. Europa supera ampliamente a los Estados Unidos en cuanto al grado de libertad otorgado por las constituciones nacionales a sus tribunales supremos. Aunque la libertad interpretativa y el activismo de la Corte Suprema de los Estados Unidos ha llevado a un distinguido decano de una escuela de derecho a señalar con aprobación que ella es el "Comité Central" 29 estadounidense, esta Constitución norteamericana todavía se concibe como un conjunto de límites negativos a los poderes de gobierno federales y estatales, más que como un programa positivo de acciones a desarrollar en todas las esferas de la actividad pública ${ }^{30}$.

No sucede lo mismo en el Viejo Mundo. Muchas de las nuevas constituciones del siglo veinte suenan como plataformas de partido, es decir, importantes programas de construcción social que el Estado tiene el deber de implementar ${ }^{31}$. Dado que es imposible saber lo que será realmente necesario en el futuro, los juicios instrumentales carecen de la certeza que distingue a las normas prohibitivas. De esta forma, un tribunal supremo encargado de aplicar un programa constitucional de carácter positivo goza de una mayor discrecionalidad que aquel otro llamado simplemente a exigir ciertas prohibiciones negativas.

En la medida que los nuevos ordenamientos constitucionales del mundo incorporen mandatos positivos para la acción del Estado, como lo hace el de Ucrania ${ }^{32}$, de igual modo se estará ampliando el poder discrecional del tribunal encargado de interpretar y hacer cumplir el orden

29 William RAY FORRESTER, anterior Decano de la Escuela de Derecho de Cornell, en "Are we ready for Truch in Judging?", en American Bar Association Journal, N ${ }^{\circ}$ 63, 1977, p. 1216. Véase, por ejemplo, la discusión de la Corte en Harris v. McRae, 448 U.S. 297, $317-18$ (1980).

31 Véase, por ejemplo, las actuales constituciones de Irlanda, España, y, fuera de Europa, India y Nepal. Sin embargo, no todas estas normas positivas pueden ser exigidas judicialmente en todos estos países.

32 Por ejemplo, la Constitución de Ucrania Artículos 43 (deber del estado de garantizar oportunidades para un trabajo seguro), 47 (derecho a vivienda), 48 (derecho a condiciones de vida satisfactorias), 50 (derecho a un ambiente seguro y saludable). 
fundamental. Por ejemplo, no resulta impensable que la nueva Corte Suprema de Ucrania pueda ordenar la reintegración económica con Rusia si estimara que es la solución más efectiva para proteger los "derechos de los consumidores" 33 , o el "derecho al trabajo, incluyendo el derecho a tener la posibilidad de ganarse la vida en un trabajo que él/ella elige o acuerda libremente" 34 .

Es probable que los ordenamientos constitucionales recientes no solo contengan deberes positivos, sino que también sean interpretados en forma programática. A diferencia de la Constitución de Estados Unidos, que se emplea básicamente como un código penal que limita la libertad del Estado solo en ciertos aspectos debidamente definidos, las nuevas constituciones están siendo interpretadas como si fueran clásicos códigos civiles, esto es, extensos regímenes que contienen en principio la solución a cualquier disputa posible. Los nuevos deberes positivos estatales e incluso privados ${ }^{35}$ están siendo descubiertos por analogía con los antiguos, y los jueces conciben el ordenamiento jurídico como una jerarquía obligatoria de valores que gobiernan toda la acción pública. El Tribunal Constitucional español ha establecido claramente las implicancias de este nuevo enfoque:

Es también pertinente hacer... algunas referencias al ámbito, significación y función de los derechos fundamentales en el constitucionalismo de nuestro tiempo inspirado en el Estado social de Derecho... Los derechos fundamentales... son la expresión jurídica de un sistema de valores que, por decisión del constituyente, ha de informar el conjunto de la organización jurídica y política... Por consiguiente, de la obligación del sometimiento de todos los poderes a la Constitución no solamente se deduce la obligación negativa del Estado de no lesionar la esfera individual o institucional protegida por los derechos fundamentales, sino también la obligación positiva de contribuir a la efectividad de tales derechos, y de los valores que representan, aun cuando no exista una pretensión subjetiva por parte del ciudadano... ${ }^{36}$

Queda claro, entonces, que cualquier intento por conferir un poder de interpretación vinculante no puede fundarse en la presunción de que

Arrículo 42.

34 Arrículo 43. Nótese que los artículos 8 y 55 ordenan la protección judicial de los derechos constitucionales. Dado que dicho mandato solo sería calificado como una "interpretación" de la Conscitución de Ucrania más que como una "modificación", el Tribunal Consritucional podría sostener que no existe infracción del artículo 157 (prohibición de reformas constitucionales tendientes a abolir la independencia de Ucrania).

35 Esto es lo que la teoría constitucional alemana denomina Drittwirkung.

$36 \quad 11$ de abril, STS 53/1985, 1985-49 BJC 515, 532, la decisión que exige una protección afirmativa del Estado para los seres humanos no nacidos. 
el tribunal será cuasi infalible, o que alcanzará sus conclusiones a través de un procedimiento científico objetivo aplicado a los textos jurídicos. Tanto el proceso de interpretación como el significado de una constitución se han vuelto tan altamente politizados hoy en día que ningún observador honesto puede desconocer el potencial de tiranía que existe en un Poder Judicial centralizado y absoluto.

Pero ¿existe alguna alternativa que no sea el desorden total? La respuesta, como veremos a continuación, es afirmativa. El "imperio del derecho" no necesita elegir entre tener un solo referente de la interpretación del derecho y no tener ninguno. Conviene analizar la posibilidad de múltiples referentes, por lo tanto de un "pluralismo jurídico".

\section{TEORÍA Y PRÁCTICA DEL PLURALISMO JURÍDICO}

El problema teórico que enfrentamos puede ser reformulado de modo muy simple. Un intérprete falible puede oscurecer o distorsionar los textos jurídicos en la medida que su interpretación se vuelva definitiva, final. La finalidad en sí misma tiene dos componentes. Un tribunal es considerado el intérprete final del derecho siempre y cuando (1) pueda controlar a todos los demás intérpretes y (2) no pueda ser revisado por ningún otro intérprete. Por lo tanto, este monopolio de poder interpretativo podría reducirse en la medida que se logre debilitar cualquiera de los dos elementos que conforman la finalidad.

La "separación de poderes" es un nombre apropiado para calificar los esfuerzos por atenuar el primer componente de supremacía judicial final. Si un tribunal supremo es privado del poder para examinar la interpretación jurídica de otras instituciones públicas, o si dicha competencia es reducida, entonces la concentración de poder interpretativo en el ápice de una sola pirámide ha quedado eliminada. Los múltiples intérpretes finales han desplazado al intérprete único, evitando de este modo que las interpretaciones jurídicas idiosincrásicas y poco convincentes sean impuestas por unos pocos sobre todos. Como veremos, existen variadas fórmulas susceptibles de ser implementadas para hacer efectiva la separación de poderes.

"Controles y equilibrios" es un término adecuado para identificar la fórmula que se opone al segundo elemento del monopolio interpretativo. En este caso, la interpretación del tribunal supremo o constitucional no tiene un carácter obligatorio o final para el resto de los actores jurídicos, dado que la revisión es recíproca. El tribunal supremo puede revisar a los demás intérpretes, pero estos también pueden controlar las decisiones del tribunal. La interpretación perversa del derecho se vuelve menos probable al aumentar el número de personas que pueden rechazar la colaboración con interpretaciones poco fidedignas. Aquí, nuevamente, existe un núme- 
ro de variantes, importantes en lo teórico y práctico, que veremos más adelante ${ }^{37}$.

Volviendo brevemente a nuestra analogía religiosa: los extremos de la supremacía papal católica y del desorden individual protestante podrían ser evitados si distintas iglesias cristianas pudieran realizar interpretaciones de la Biblia independientes, o si aquellas iglesias tuvieran que aprobar en forma recíproca las interpretaciones de las otras. La tradición ortodoxa oriental ha utilizado elementos de ambos sistemas, incorporando tanto la autonomía relativa entre los patriarcas como la necesidad de un continuo reconocimiento mutuo por parte de esas mismas iglesias hermanas.

Al analizar, en primer lugar, la separación de poderes, es posible identificar dos modelos principales. El primero otorga a ciertos órganos el poder de interpretar el derecho sin estar sujetos a ningún tipo de revisión. El segundo modelo admite un cierto grado de control sobre el intérprete, pero rechaza la concentración del poder final de revisión en un solo organismo.

En el mundo existen variados ejemplos de la primera modalidad. Las limitaciones en materia de legitimación procesal activa constituyen una clara muestra de este fenómeno. En Estados Unidos, para alegar una cuestión constitucional $^{38}$, se requiere un interés jurídicamente protegido en el resultado de la acción; en Francia, solo algunas entidades políticas pueden impugnar la constitucionalidad de los proyectos de ley ${ }^{39}$; asimismo, en Ucrania, la constitución restringe severamente la legitimación activa en asuntos de carácter constitucional, dado que se reconoce en forma exclusiva a ciertos funcionarios e instituciones ${ }^{40}$. De esta forma, el acceso restringido a los tribunales de justicia favorece que los actores políticos y jurídicos puedan desarrollar sus interpretaciones de manera libre y exenta de control. En un plano más doméstico, el jurado que conoce de un caso criminal en Estados Unidos tiene el deber de aplicar el derecho, pero si absuelve al acusado su interpretación jurídica no admite ulterior recurso ${ }^{41}$.

37 Christopher WOLFE: The Rise of Modern Judicial Review, edición revisada, Rowman and Littlefield Publishers, Inc., Lanham, Maryland, 1994. Agradezco especialmente al autor por el análisis que sigue a continuación, aunque la terminología utilizada no se encuentra en WOLFE. Véase especialmente su discusión en "Alternatives to Judicial Review", 90-96.

Cose, e.g., Flast v. Cohen, 392 U.S. 83 (1968).

39) Constitución de la República de Francia de 4 de octubre de 1958, Artículo 61 (modificado en 1974).

40) Constitución de Ucrania, Artículo 150(1).

41 El Estado no puede apelar un veredicto general de "no culpable", incluso en aquellos casos en que el jurado ha ignorado claramente la interpretación jurídica del juez. Véase la discusión a fondo sobre esta conducta del jurado, en U.S. v. Thomas, 116 F.3d 606 C.A.2 (N.Y.) 1997 , donde el tribunal concede que esta negativa de parte del jurado ha sido considerada a veces "como una expresión de fidelidad al derecho más que un desafío al mismo..." 
Un ejemplo más sustantivo lo constituye la sustracción de las "cuestiones políticas" del conocimiento de la Corte Suprema estadounidense. En aquellos casos, el Congreso está autorizado para aplicar la Constitución por sí mismo ${ }^{42}$. A mayor abundamiento, la categoría completa de deberes constitucionales positivos que otorgan un mandato al legislador puede gozar de inmunidad jurisdiccional ${ }^{43}$. De este modo se impide el control judicial de la interpretación legislativa de tales deberes (y se evitan varios de los conflictos entre efectividad e imperio del derecho). En otras palabras, algunos deberes constitucionales del legislador podrían quedar sujetos a la interpretación y revisión del máximo tribunal, pero otros simplemente no.

Desde luego, en regímenes donde se controla la constitucionalidad de leyes comunes u ordinarias es muy común que las reformas constitucionales permanezcan prácticamente inmunes a la revisión judicial. Los tribunales no necesitan asumir la función de control constitucional ni siquiera en lugares donde se prohíbe expresamente un determinado tipo de reforma a la Carta Fundamental, como en el caso de Noruega ${ }^{44}$.

En naciones modernas como Gran Bretaña e Israel es ampliamente conocida la prolongada ausencia de control judicial de la legislación ordinaria. Ellas han poseído constituciones no escritas, pero sus legisladores han tenido el deber de controlar la inconstitucionalidad por ellos mismos. Los tribunales, por su parte, revisaban la constitucionalidad de las actuaciones administrativas. Este modelo de separación de poderes no es exclusivo de países con constitución consuetudinaria. Por ejemplo, la constitución escrita de Francia favoreció durante mucho tiempo un régimen de control constitucional limitado o prácticamente inexistente; sus legisladores estaban sometidos únicamente a la Constitución, prescindiendo de otros intérpretes humanos ${ }^{45}$. Incluso hoy, la legislación francesa ya promulgada no puede ser declarada inconstitucional por ningún tribunal de la República. (El Consejo Constitucional de Francia podría

42 Véase Baker v. Carr, 369 U.S. 186(1962).

43 Por ejemplo, esa es - al menos nominalmente- la regla que se encuentra en la Constitución de India en consideración a la larga lista de "Principios Rectores de la Política del Estado". El artículo 37 declara que estos principios "no podrán ser exigidos ante ningún tribunal".

44 El artículo 12 de la Constitución de Noruega establece que ninguna modificación es válida si altera "el espíritu de la Constitución". Pero la interpretación mayoritaria de esta cláusula es que solo se trata de un mandato al legislador, es decir, no faculta a ninguna corte u otro tribunal para rechazar la validez de una reforma. Véase D. ConraD: "Limitation of Amendment Procedures and the Constituent Power", Indian Yearbook of International Affairs, $\mathrm{N}^{\circ} 15-16,1970$, pp. 379-80.

is A modo general, véase Louis HenKIN: "Revolutions and Constitutions", 49, Louisiana Law Review pp. 1023, $1044-46$ (1989). Para el argumento clásico en contra del control judicial de consticucionalidad de la ley, ver el voto disidente del Chief Justice John Gibson en Eakin v. Raub, 12 Serg \& Rawle 330 (Pa. 1825). 
impedir un cambio en el derecho mediante la invalidación de un proyecto de ley, pero carece de atribuciones para alterar las leyes vigentes $\left.{ }^{46}\right)$. La nueva constitución de Ucrania parece proteger el derecho vigente de manera diferente: aunque el Tribunal Constitucional puede declarar inconstitucional cualquier ley, antigua o nueva, dicha declaración solo producirá efectos hacia el futuro ${ }^{47}$. De este modo, los funcionarios del Estado y el público saben que pueden confiar en la validez de las leyes que regulan el desarrollo de sus actividades en el presente; así también, se elimina gran parte de la naturaleza ílicita ex post facto (retrospectiva) de la legislación de la Corte. El tribunal Ucraniano aun podría transformarse en un tirano, pero tendrá que ejercer su voluntad conforme al "imperio del derecho", i.e. dando aviso previo antes de sustituir una ley por una opinión judicial.

Los ejemplos anteriores plantean una serie de interrogantes. ¿Es realmente aconsejable atribuir el carácter de jueces únicos del derecho, incluyendo la constitucionalidad de sus propias decisiones, a actores políticos que se interesan principalmente en los resultados? ¿No sería como permitir un sistema de juez en causa propia? La interpretación del derecho de dichos actores ¿no debería ser controlada por algunos órganos desinteresados, o al menos con un interés menor? Una respuesta afirmativa a estas preguntas tiene mucho mérito. Sin embargo, aunque sea buena idea establecer un sistema de apelaciones imparciales, no resulta indispensable que tales procesos finalicen en un tribunal supremo único. Por ejemplo, se podría establecer un propio consejo parlamentario, independiente de los tribunales ordinarios, para examinar la constitucionalidad de los proyectos de ley, tal como ha sucedido en Francia con su Consejo Constitucional y en Chile con su Tribunal Constitucional. Una constitución también podría distribuir de otras maneras la jurisdicción sobre cuestiones constitucionales entre distintos tribunales. Este es el caso de Francia hoy en día, donde el Consejo Constitucional está facultado para controlar solamente los proyectos de ley, mientras que el Consejo de Estado se pronuncia acerca de la constitucionalidad de las actuaciones y regulaciones administrativas ${ }^{48}$. Asimismo, en Chile, el régimen de Pinochet estableció un Tribunal Constitucional con atribuciones para

\footnotetext{
46 Arrículo 61, op. cit.

47 Artículo 152. Sin embargo, el mismo artículo contempla una indemnización por leyes inconstitucionales, lo que parece dar efecto retroactivo a la declaración de invalidez.

48 La profesora de derecho de Harvard Mary Ann Glendon ha denominado al Consejo de Estado "un segundo tribunal constitucional de Francia". Comparative Legal Traditions, 2nd ed., editada por M.A. Glendon et al., West Publishing Co., St. Paul, 1994, p. 120. Véase también el excelente arcículo del canadiense F.L. MORTON, "Judicial Review in France: A Comparative Analysis", American Journal of Comparative Law, $\mathrm{N}^{\circ} 36,1988$, p. 89. MORTON concluye que "es hora de que los constitucionalistas americanos y europeos conciban el control constirucional como el 'género' y al modelo americano solo como una 'especie' (la variación judicial) de dicho género" Id., p. 10.
} 
invalidar proyectos de ley con efectos erga omnes. Sin lugar a dudas, esta nueva institucionalidad permitía evitar propuestas de inspiración socialista. Por su parte, la Corte Suprema puede declarar la inconstitucionalidad de un precepto legal vigente, pero solo con efecto obligatorio para las partes del conflicto, dado que las decisiones del máximo tribunal no producen stare decisis o efecto erga omnes ${ }^{49}$. De esta forma, tanto en Francia como en Chile podrían desarrollarse fácilmente dos visiones acerca del significado de la Constitución, siendo cada una susceptible de ser aplicada en un ámbito jurídico distinto. No existen motivos para que se produzca un conflicto o desorden. Las claras divisiones jurisdiccionales permitirían conservar el pluralismo de pensamiento jurídico. Nadie en Francia o en Chile podría sostener que "la Constitución significa solo lo que los jueces dicen que significa", dado que dos instancias finales podrían diferir en dicho significado.

Un cierto grado de pluralismo podría asegurarse incluso en naciones donde existe un intérprete único de la Constitución, en la medida que dicho órgano no sea paralelamente el intérprete final de todo el ordenamiento jurídico de rango inferior. En este punto los ejemplos abundan. Los tribunales constitucionales de Alemania, España, e Italia parecen ser ciertamente los intérpretes finales y obligatorios de la Constitución, pero una o más cortes supremas separadas podrían ser las intérpretes finales de las otras ramas del derecho ${ }^{50}$. Incluso en los Estados Unidos, donde la Corte Suprema reclama el poder de interpretación final sobre la Constitución y la legislación federal también, la interpretación del derecho de los distintos estados ha sido confiada a las cincuenta cortes supremas estatales. En este tipo de régimen federal, ningún magistrado puede imponer su manera de entender el derecho en todo el sistema jurídico, de ahí que es probable que el pluralismo de enfoque interpretativo sobreviva. Desafortunadamente, este no sería el caso de Ucrania, donde se ha confiado la interpretación obligatoria de todo el ordenamiento jurídico (Constitución y normas de rango inferior) a un Tribunal Constitucional único ${ }^{51}$.

Una crítica que se podría formular al método de separación de poderes para evitar la tiranía judicial es que acorta el proceso de apelación -eliminando la cima de la pirámide judicial-permitiendo de este modo que los errores interpretativos de otros tribunales o instituciones se consoliden más fácilmente. Sin embargo, este no es un argumento poderoso en contra de la separación de poderes. Si se estima imprescindible que existan al menos dos apelaciones para que la interpretación jurídica sea definitiva, este objetivo

\footnotetext{
49 La Constitución Política de la República de Chile (1980), Artículo 82 y Artículo 80 respectivamente.

50 En Iralia existe una Corte de Casación separada, como en Francia, mientras que en España el máximo tribunal no constitucional es llamado Tribunal Supremo. Alemania cuenta a nivel federal con cinco cortes de apelación final no constitucionales (incluyendo la máxima corte administrativa). Artículos 147 y $150(2)$.
} 
podría ser alcanzado fácilmente sin necesidad de confiar la apelación final de cada asunto al mismo tribunal. En definitiva, el requisito fundamental de la separación de poderes es la división del proceso de apelación, no su reducción.

Una crítica más profunda sería la siguiente: no importa mucho si el poder de interpretación final está concentrado en un tribunal único o distribuido entre muchas instituciones, porque los otros oficiales y el resto de la ciudadanía de todas formas no están sujetos al derecho mismo sino a las interpretaciones jurídicas de seres humanos falibles. ¿Deseamos realmente que nuestros oficiales o ciudadanos obedezcan ciegamente lo que ellos perciben como interpretaciones del derecho claramente erróneas, aun cuando aquellas interpretaciones sean potencialmente menos despóticas porque emanan de fuentes múltiples? Aunque se considere mejor que el Presidente de Francia esté sometido a la interpretación constitucional de dos tribunales (el Consejo Constitucional y el Consejo de Estado) en vez de uno solo, ¿que pasaría si él pensara que ambos organismos están equivocados? ¿No debería tener un deber especial de no infringir la Constitución según como él mismo la percibe?

A esta línea de razonamiento responde el método "controles y equilibrios" con el objeto de limitar el poder del tribunal supremo. La idea esencial consiste en dotar a múltiples intérpretes no con poderes divididos para determinar el significado del derecho, sino con un poder conjunto. Por ejemplo, en vez de establecer una cuidadosa distribución de la potestad para interpretar la Constitución entre los poderes Legislativo, Ejecutivo y Judicial (el enfoque de la separación de poderes), una nación podría imponer a las tres ramas el deber de no participar en ninguna ley inconstitucional, el deber de ser fieles a todos los aspectos de la Carta Fundamental más que a una sola parte. De esta forma, la Corte Suprema tendría la obligación de no aplicar una ley que contraviene la Constitución, mientras que el legislador y el ejecutivo tendrían un cometido similar de no ejecutar resoluciones inconstitucionales de la Corte Suprema. Cada vez que una acción de gobierno exigiera la cooperación de los tres poderes públicos sería necesario un consenso acerca del significado de la Constitución. Ahora bien, con ello disminuiría el riesgo de una acción inconstitucional del Estado, pero aumentaría el grado de estancamiento de la gestión pública. Sin embargo, en eso consisten precisamente los controles y equilibrios, en equilibrar poder contra poder, un equilibrio que proviene no de intereses en conflicto, sino de la común fidelidad al mismo derecho básico.

Las limitaciones tipo "controles y equilibrios" que contempla este artículo pueden expresarse bajo una fórmula muy simple: eliminare o reducir los efecto jurídicos parecidos a stare decisis (precedente obligatorio).

La forma más radical del stare decisis (horizontal y vertical combinados), es decir, aquella que obliga no solo a las partes destinatarias de la decisión y a los tribunales inferiores, sino incluso al propio tribunal que la emite, 
resulta particularmente peligrosa en un contexto constitucional. Los errores de interpretación se vuelven tan arraigados que ni siquiera pueden ser controlados y corregidos por el tribunal supremo que los cometió, a menos que el procedimiento de reforma constitucional pueda ser utilizado en forma fácil y frecuente.

En su versión puramente vertical, el stare decisis obliga a cada tribunal u otra institución a respetar la decisión de la corte superior, pero no obliga a la corte misma respecto de su decisión. El efecto de esta modalidad también es irracional y peligroso por lo menos en el ámbito constitucional. El carácter vinculante de la interpretación jurídica de un tribunal supremo implica que, aunque el tribunal supremo pueda cambiar de opinión si descubre un error anterior, resulta improbable que los tribunales inferiores le hagan saber dicha infracción. Los jueces inferiores tienen que cumplir las resoluciones del tribunal supremo en forma ciega, sin considerar su propia opinión al respecto. De esta forma, el litigio sobre un asunto ya decidido por el máximo tribunal se vuelve casi inútil. En general, la corte de mayor jerarquía en un sistema de stare decisis vertical se resiste a conocer cualquier objeción a sus interpretaciones jurídicas anteriores, tal como si se tratara de un dictador que se ha negado a recibir noticias sobre el descontento popular.

La revisión judicial de las leyes no necesita incorporar ninguna versión del stare decisis. Puede existir un sistema en que una corte constitucional esté facultada para invalidar una ley para las partes pero no para todo el mundo en el futuro, como el sistema que ha existido en Chile con su Corte Suprema. Fue muy semejante la reconceptualización de la Corte Suprema norteamericana que hizo el presidente Abraham LiNCOLN para resistir la sentencia en el caso Dred Scott, que había negado la ciudadanía a los negros libres. Lincoln aceptó el efecto de la sentencia sobres las partes, pero negó su efecto vinculante para el futuro. Es decir, el Presidente seguía reconociendo a los negros como ciudadanos en otros contextos, negando así su cooperación con el dictamen de la Corte Suprema. Claro que la Corte puede volver a anular repetidamente la ciudadanía de cada negro, pero por lo menos tiene que trabajar. Es un muy buen ejemplo de equilibrio o balance de poderes.

Incluso, podría existir una potestad judicial para declarar una ley inconstitucional con efecto erga omnes -i.e. para toda la nación- sin que esta interpretación de la Carta Fundamental produzca efectos vinculantes hacia el futuro. De esta forma, el legislador permanece libre para elaborar una nueva ley que contradiga la interpretación constitucional del tribunal. Por supuesto, el alto tribunal también podría anular esta nueva ley, pero en la medida que el tribunal actúe solo con la fuerza y no con el convencimiento, el legislador puede seguir insistiendo para que replantee su opinión en muchos contextos $^{52}$.

32 No sabemos exactamente lo que sucederá con la Constitución de Ucrania. El Tribunal Constitucional es el encargado de realizar la "interpretación oficial de la Constitución de 
¿Qué personas o instituciones están debidamente autorizadas para controlar y equilibrar lo que ellas perciben como errores constitucionales del Tribunal Supremo? Hemos estado hablando de las otras ramas del gobierno, el Legislativo y el Ejecutivo. Pero no debemos olvidar al propio Tribunal Supremo. La falta de vinculación horizontal puede parecer de poca importancia en un sistema como el norteamericano, donde los jueces del tribunal tienen carácter vitalicio ${ }^{53}$. Si los mismos señores se encuentran con el mismo problema, es poco probable que cambien la idea. Pero la falta de stare decisis horizontal podría ser mucho más significativa en aquellos regímenes que (a diferencia de los Estados Unidos de América) mantienen un recambio frecuente de los miembros del Tribunal en cuestión. En Ucrania, la Constitución establece un período de solo nueve años para cada juez del Tribunal Constitucional $^{54}$. Si la doctrina horizontal del stare decisis no impone limitaciones al Tribunal Constitucional de Ucrania, entonces sus interpretaciones no son tan "obligatorias" después de todo. En efecto, ellas podrían ser "apeladas" ante un panel de jueces completamente distinto nueve años más tarde.

Ahora que las versiones horizontal y vertical de la doctrina stare decisis han sido rechazadas con el objeto de garantizar al Ejecutivo y al legislador, y a un tribunal futuro, la libertad para resistir órdenes inconstitucionales de una Corte Suprema, surgen más preguntas. ¿No debería poder resistir también un estado miembro de una federación? Eso es lo que sucedió durante muchas décadas en los EE.UU, en el siglo diecinueve, y en Europa este siglo (cuando a los estados miembros de la Unión Europea les parecía que la U.E. y su Tribunal de Justicia actuaban ultra vires). E incluso, ¿por qué los seres humanos comunes permanecen obligados a respetar mandatos que les parecen plenamente antijurídicos?55 $\mathrm{Si}$ la Constitución obliga directamente, por encima de las interpretaciones de un Tribunal Constitucional, entonces

Ucrania y de las leyes de Ucrania", junto con examinar la constitucionalidad de los reglamentos y actuaciones del Ejecutivo. Aparentemente, las decisiones del Tribunal en materia de interpretación jurídica y de conformidad a la Constitución son "obligatorias en todo el territorio de Ucrania", "definitivas", "y no podrán ser apeladas". Si el Tribunal solo tuviera competencia para invalidar una ley con efecto erga omnes, la cláusula que se refiere a la interpretación sería innecesaria. Por lo tanto, pareciera que las decisiones del juez supremo producen el efecto de stare decisis en su versión vertical, es decir, obliga a los demás sujetos para siempre. Incluso, si no fuera por el ambiente anti-stare decisis europeo que predomina en Ucrania, uno también podría suponer que la Constitución obliga al tribunal respecto de sus propias decisiones. Después de todo, sus sentencias son "obligatorias en todo el territorio de Ucrania", $y$ acaso el Tribunal no tiene su sede sino "en el territorio de Ucrania" como cualquier orra institución?

En los EE.UU., los jueces de la Corte Suprema son designados de por vida, a menos que sean juzgados y removidos por el Congreso (situación que nunca ha ocurrido). Artículo 148.

Desde luego, la norma jurídica podría ser establecida para limitar la resistencia a determinadas instituciones. En cierto sentido, esto es lo que ha hecho Canadá. Cuando la Corte Suprema de Canadá sostiene que una ley es inconstitucional, el legislador afectado podría no obstante votar para mantenerla vigente. Constitución de Canadá (1982), I Parte, Arrículo 33. 
cada ciudadano debe ser tan libre como cada Presidente para resistir las interpretaciones gravemente erróneas de dicho Tribunal. Ciertamente. Como se señaló, la resistencia de aquel ciudadano a las decisiones inconstitucionales parece ser exactamente lo que reconoce el Derecho Básico de Alemania. Reiteramos, la Sección 20(4) de aquella Constitución establece que "todos los alemanes tienen el derecho de resistir a cualquier persona o personas que pretendan abolir el orden constitucional, no existiendo otra vía de protección posible". Entonces, si los tribunales optaran por apoyar un régimen contrario a la Constitución, y ya se han agotado todos los medios disponibles, la resistencia del ciudadano estaría plenamente autorizada.

¿Estamos volviendo de este modo al desorden que rechazamos al comienzo de este artículo, al invocar un "derecho de resistencia"? No. Por lo menos no es así si atendemos cuidadosamente a la distinción entre res judicata y stare decisis. Si cada ciudadano tuviera el derecho de resistir interpretaciones jurídicas erróneas en un caso particular, bien podría surgir el caos, aunque en circunstancias muy extremas, como de las de la Alemania nazi, el desorden podría constituir posiblemente el mal menor. Sin embargo, si cada ciudadano gozara de libertad solamente para pensar en el significado de la Constitución o del derecho en los casos futuros, si fuera libre para resistir cualquier forma de stare decisis, él o ella simplemente tendría un derecho de solicitar a los funcionarios del Estado y a los tribunales la revisión de doctrinas ya decididos por el máximo tribunal, lo que no es en absoluto una doctrina radical. Un Tribunal Supremo que estuviera convencido de su propia rectitud todavía estaría en condiciones de forzar a cada disidente a cumplir con sus mandatos. Pero si pretende obtener una colaboración voluntaria con sus decisiones, tiene que convencer a sus oyentes de que realmente habló en nombre de la Constitución.

Aunque el poder de interpretación final estuviese dividido, como se ha sugerido, los ciudadanos podrían conservar sin inconvenientes el derecho a cuestionar las múltiples interpretaciones jurídicas de los distintos poderes, no en relación con las partes de un determinado caso, sino que con efectos hacia el futuro. ¿Por qué una interpretación constitucional sostenida por el legislador acerca de los requisitos de su propio quórum constitucional o de los derechos sociales afirmativos tendría que ser obligatoria para todos? Existen mayores probabilidades de prevenir una tiranía grande o pequeña en la medida que el poder de interpretar el derecho sea dividido y también equilibrado.

En la medida que disminuya la distinción entre derecho y política, la necesidad de distinciones dentro del derecho aumenta. En la medida que el intérprete judicial se atribuya mayores cuotas de poder político, el pluralismo en la interpretación jurídica se vuelve más necesario. Ningún tribunal debería poseer la facultad de imponer interpretaciones politizadas del derecho a toda una nación. 
Este artículo ha analizado dos alternativas confiables frente al modelo de autoridad de interpretación concentrada. La alternativa de "separación de poderes" sostiene que el poder de interpretar y aplicar la Constitución y las leyes se debe otorgar a un número de instituciones jurisdiccionalmente distintas. De este modo, la multiplicidad de intérpretes contribuye a preservar el pluralismo en el pensamiento jurídico, una libertad frente a la dominación de cualquier ideología jurídica.

Por su parte, la fórmula de los "controles y equilibrios", que ha sido sugerida, implica que cada interpretación del derecho (o al menos la del Derecho Constitucional) es obligatoria solamente en relación con las materias controvertidas de un caso particular, sin generar el efecto de stare decisis hacia el futuro. De esta forma, los esfuerzos de un intérprete, o de muchos intérpretes, por dominar y controlar los desarrollos políticos futuros, podrían ser revisados y equilibrados según su grado de fidelidad a la Constitución y a las leyes, en todas aquellas situaciones en que se aparten gravemente de la fuente de su autoridad.

Tanto la separación de poderes como el sistema de controles y equilibrios, o preferiblemente ambos, permiten implementar alternativas viables para prevenir la tiranía judicial. El pluralismo jurídico es el punto medio práctico entre el absolutismo jurídico y la anarquía jurídica.

\section{BIBLIOGRAFÍA CONSULTADA}

- D. ConRaD: "Limitation of Amendment Procedures and the Constituent Power", Indian Yearbook of International Affairs, $\mathrm{N}^{\circ}$ 15-16, 1970.

- Jacques Derrida: Of Grammatology, Gayatri Chakravorty Spivak trans, John Hopkins Press, Baltimore, 1976.

- Catherine Drinker Bowen: The Lion and the Throne, Little, Brown and Company, Boston, 1956..

- Thomas JefFerson: Carta a Abigail Adams, 8 Writings of Thomas Jefferson, Ford. Ed., 1897; en Paul BREST, Processes of Constitutional Decisionmaking, Little, Brown and Company, Boston, 1975.

- William W. FISHer III et al: American Legal Realism, editado por, Oxford University Press, New York, 1993.

- William Ray FORRESTER: Are we ready for Truth in Judging?, en American Bar Association Journal, № 63, 1977.

- Mary Ann Glendon: Comparative Legal Traditions, $2^{\text {nd }}$. Ed., editada por M.A. Glendon et al., West Publishing Co., St. Paul, 1994.

- H. L.A. Hart: The Concept of Law, $2^{\text {nd }}$ ed., Oxford University Press, 1994.

- John HART ElY: Democracy and Distrust, Harvard University Press, 1980. 
- Mortimer R. Kadish y Sanford H. Kadish: Discretion to Disobey, Stanford University Press, 1973.

- J. M. Kelly: A Short History of Western Legal Theory, Clarendon Press, Oxford; Oxford University Press, New York, 1992.

- Sanford Levinson: Constitucional Faith, Princeton University Press, 1988.

- Abraham Lincoln: Messages and Papers of the Presidents, RiCHARDSON ed., 1897; en Paul Brest, Processes of Constitutional Decisionmaking, Little, Brown and Company, Boston, 1975.

- Jean-Francois Lyotard: The Postmodern Condition: A Report on Knowledge, Geoff Bennington y Brian Massumi trans., University of Minnesota Press, 1979.

- John Henry Merryman: The Civil Law Tradition, $2^{\text {nd }}$ ed., Stanford University Press, 1985.

- F. L. MORTON, "Judicial Review in France: A Comparative Analysis", American Journal of Comparative Law, $\mathrm{N}^{\circ}$ 36, 1988.

- Christopher NORRIS y Andrew BENJAMIN: What is Deconstruction?, St. Martin's Press, New York, 1989.

- Christopher OSAKWE: "Contemporary Soviet Criminal Law: An Analysis of the General Principles and Major Institutions of Post1958 Soviet Criminal Law", Georgia Journal of International and Comparative Law, $\mathrm{N}^{\circ}$ 6, 1976.

- Edward A. Purcell, Jr.: The Crisis of Democratic Theory, capítulos 5 y 9, University Press of Kentucky, 1973.

- Richard STITH y J. H. H. WeIleR: Dos visiones norteamericanas de la jurisdicción de la Unión Europea, Universidad de Santiago de Compostela, 2000.

- Christopher Wolfe: The Rise of Modern Judicial Review, edición revisada, Rowman and Littlefield Publishers, Inc., Lanham, Maryland, 1994.

- Louis Henkin: "Revolutions and Constitutions", Louisiana Law Review, 1989.

- Franz WieAcKer: "Foundations of European Legal Culture", traducida y concordada por Edgar Bodenheimer, en American Journal of Comparative Law, $\mathrm{N}^{\circ}$ 38, 1990.

- Hessel E. Yutema: "The Hornbook Method and the Conflict of Laws", Yale Law Journal, $\mathrm{N}^{\circ} 37$. 